\title{
ATTRIBUTES OF FAMILY RELATIONS
}

\section{T Arun Christopher ${ }^{1 *}$}

${ }^{1}$ Assistant Professor, School of Education Central University of Kashmir, Ganderbal, Jammu \& Kashmir.

\begin{abstract}
The purpose of this study is to explore and develop model for family relations. The sample of this study constituted 1300 higher secondary students from government, government aided and private schools from Kanchipuram district of Tamil Nadu. Walter Hudson family relations scale was administered to collect the data. Analysis of data shows the developed model constitute five attributes for family relations viz., family misunderstanding, family support, family distrust, family interaction and family isolation.
\end{abstract}

Keywords

Family relations, Family understanding, family support, family distrust, family interaction and family isolation, higher secondary students' family relations, Adolescence family relations, Attributes of family relations.

\section{Introduction}

Family is a single unit of people who live together and share life's basic day-by-day functions. Humanities has demonstrated the need for such a core group, yet also has demonstrated need for each individual member to grow. These dual, sometimes contrasting, human needs create the paradoxes of the family unit, in which exists struggle for separateness and togetherness, differentness and sameness, protection and freedom, support and independence (Dodson 1977). Higher secondary adolescents are an age where relations undergo significant transformation. The adolescent child feels comfortable and emotionally connected more to members outside the family (Jude J. Obiunu, 2015). There is a gradual drift in level of relations between adolescent and family. Arguably psychologists consider this to be common during adolescents' stage. This investigation will help to identify the attributes of family relations in the eyes of higher secondary adolescents of Kanchipuram district, Tamil Nadu.

\section{Objective}

The main objective of this study was to explore the factors of family relations among higher secondary school students of Kanchipuram District, Tamil Nadu, India.

\section{Operational Definitions}

a. Family relations - Interpersonal relations that exist between the members of the family.

b. Higher Secondary Students - It refers to adolescents studying class XI and class XII between the age group of 16 to 18 years.

c. Attributes - It describes the characteristics of a particular variable, here family relations.
This is also referred as factors or constructs in this paper.

\section{Methodology}

Exploratory factor analysis is used for this study. It helped to identify the latent variables and label them based on research reviews.

\section{Participants}

Participants of the study were 1300 higher secondary school students from Kanchipuram district of Tamil Nadu, India. The sample constitute students from government, government-aided and private schools. The acquired data is being used to develop the attributes of family relations.

\section{Instrument}

Data is collected by using Walter Hudson 'Index of family relations' was validated in the present context. This measurement consists of 25 items. The response scale is a five-point Likert scale questionnaire, ranging from strongly agree $(=5)$ to strongly disagree $(=1)$.

\section{Data Analysis}

Data are subjected to descriptive analysis. Content validity and reliability of the items were tested using SPSS 16. To explore the most reliable items and to classify the attributes of family relations exploratory factor analysis is employed.

\section{Statistical Techniques Adopted for the Study}

To explore the attributes of family relations the following statistical techniques were adopted.

Cronbach's Alpha's reliability test, Kaiser-MeyerOlkin (KMO) Measure of Sampling Adequacy and Bartlett's Test of Sphericity, Principal Component Analysis for identifying most relevant items, and 
Rotated Component Matrix for extracting and labelling of factors.

\section{Exploratory Factor Analysis}

Exploratory factor analysis (EFA) is a procedure for data examination and it determines the structure of factors to be investigated. It is utilised to determine convergent and discriminant relationship between items and factors. Here exploratory factor analysis is performed on identifying family relation aspects. To justify the application of EFA in the study the measure of sampling adequacy, a statistical test to quantify the extent of inter correlation among the variables was utilised. Hence the Barlett test of sphericity and Kaiser - Meyer - Olkin (KMO) indicate the measure of sampling adequacy. The Barlett test of sphericity is significant at $\mathrm{p}<0.05$ from the exploratory factor analysis to be considered appropriate and $\mathrm{KMO}$ is more than 0.7 is suitable for factor analysis.

\begin{tabular}{|l|l|l|}
\hline \multicolumn{2}{|l|}{ KMO and Bartlett's Test } \\
\hline $\begin{array}{l}\text { Kaiser-Meyer-Olkin } \\
\text { Adequacy. }\end{array}$ & Measure of Sampling & .837 \\
\hline $\begin{array}{l}\text { Bartlett's Test of } \\
\text { Sphericity }\end{array}$ & Approx. Chi-Square & 1.7804 \\
\cline { 2 - 3 } & Df & 190 \\
\cline { 2 - 3 } & Sig. & .000 \\
\hline
\end{tabular}

\section{Source: Computed Primary Data}

KMO value of 0.837 indicated that factor analysis was appropriate to utilise for analysing the family relation items. It is also learnt from the table that the Barlett test of sphericity is less than 0.05 indicates that the correlation matrix is significant. These conditions permitted to conduct factor analysis.

\begin{tabular}{|l|l|l|}
\hline \multicolumn{2}{|l|}{ Communalities } \\
\hline Variable & Initial & Extraction \\
\hline FSS1 & 1.000 & .804 \\
\hline FSS2 & 1.000 & .827 \\
\hline FSS3 & 1.000 & .759 \\
\hline FSS4 & 1.000 & .758 \\
\hline FINT1 & 1.000 & .664 \\
\hline FINT2 & 1.000 & .764 \\
\hline FINT3 & 1.000 & .779 \\
\hline FAUD4 & 1.000 & .762 \\
\hline FAUD5 & 1.000 & .758 \\
\hline
\end{tabular}

Total Variance Explained

\begin{tabular}{|l|l|llll|llll|}
$\begin{array}{l}\text { Compo } \\
\text { nent }\end{array}$ & Initial Eigen values & $\begin{array}{l}\text { Extraction } \\
\text { Loadings }\end{array}$ & Sums of & Squared & $\begin{array}{l}\text { Rotation } \\
\text { Loadings }\end{array}$ & Sums & of & Squared \\
\hline
\end{tabular}

\begin{tabular}{|l|l|l|}
\hline FAUD3 & 1.000 & .811 \\
\hline FAUD2 & 1.000 & .797 \\
\hline FAUD1 & 1.000 & .824 \\
\hline FADU6 & 1.000 & .701 \\
\hline FDST1 & 1.000 & .774 \\
\hline FDST2 & 1.000 & .754 \\
\hline FDST3 & 1.000 & .758 \\
\hline FDST4 & 1.000 & .728 \\
\hline FIS1 & 1.000 & .846 \\
\hline FIS2 & 1.000 & .853 \\
\hline FIS3 & 1.000 & .831 \\
\hline $\begin{array}{l}\text { Extraction } \\
\text { Analysis. }\end{array}$ & Method: Principal Component \\
\hline
\end{tabular}

FAUD - Family Misunderstanding; FIS - Family Isolation; FSS- Family Support; FDST- Family Distrust; FINT - Family Interaction

A principal component analysis was utilised to determine each variable loaded above 0.7 (since the $\mathrm{KMO}$ measure of sampling adequacy was 0.837 ). It is observed that out of 20 items except one item (FINT1) which is loaded below 0.7 and remaining items were loaded above 0.7. Communalities indicate how much one variable is accounted for by the underlying factors taken together.

\section{Extraction of Factors}

Through the principal component analysis, there were five factors in total extracted and their factor rotation sum of square loadings along with extraction sum of squared loadings are shown in Table below.

The table shows the total variance explained by each of the extracted components. A component is represented by all the variation in each of the variables. 


\begin{tabular}{|c|c|c|c|c|c|c|c|c|c|}
\hline & Total & $\begin{array}{l}\% \\
\text { Variance }\end{array}$ & of $\left.\right|_{\%} ^{\text {Cumulative }}$ & Total & $\begin{array}{l}\% \\
\text { Variance }\end{array}$ & of $\begin{array}{l}\text { Cumulative } \\
\%\end{array}$ & Total & $\begin{array}{l}\% \text { of } \\
\text { Variance }\end{array}$ & $\begin{array}{l}\text { Cumulative } \\
\%\end{array}$ \\
\hline 1 & 4.694 & 23.472 & 23.472 & 4.694 & 23.472 & 23.472 & 4.322 & 21.612 & 21.612 \\
\hline 2 & 3.848 & 19.241 & 42.713 & 3.848 & 19.241 & 42.713 & 3.286 & 16.431 & 38.043 \\
\hline 3 & 3.017 & 15.083 & 57.796 & 3.017 & 15.083 & 57.796 & 3.030 & 15.152 & 53.196 \\
\hline 4 & 2.530 & 12.650 & 70.446 & 2.530 & 12.650 & 70.446 & 2.633 & 13.166 & 66.361 \\
\hline 5 & 1.363 & 6.815 & 77.261 & 1.363 & 6.815 & 77.261 & 2.180 & 10.900 & 77.261 \\
\hline 6 & .595 & 2.975 & 80.236 & & & & & & \\
\hline 7 & .467 & 2.333 & 82.570 & & & & & & \\
\hline 8 & .403 & 2.016 & 84.586 & & & & & & \\
\hline 9 & .380 & 1.899 & 86.484 & & & & & & \\
\hline 10 & .359 & 1.795 & 88.280 & & & & & & \\
\hline 11 & .330 & 1.652 & 89.932 & & & & & & \\
\hline 12 & .305 & 1.525 & 91.456 & & & & & & \\
\hline 13 & .273 & 1.365 & 92.822 & & & & & & \\
\hline 14 & .270 & 1.349 & 94.171 & & & & & & \\
\hline 15 & .250 & 1.251 & 95.421 & & & & & & \\
\hline 16 & .231 & 1.155 & 96.576 & & & & & & \\
\hline 17 & .194 & .970 & 97.546 & & & & & & \\
\hline 18 & .184 & .920 & 98.467 & & & & & & \\
\hline 19 & .159 & .797 & 99.263 & & & & & & \\
\hline 20 & .147 & .737 & 100.000 & & & & & & \\
\hline
\end{tabular}

Each variable is standardised with the maximum variance for each as 1.0. An Eigen value reflects the proportion of variance explained by the component. Kaiser's criterion (Kaiser, 1958) specified that only components with an Eigen value of 1.0 or greater should be retained for analysis. 
Eigen component with an Eigen value of 1.0 or greater explain $77.261 \%$ of the total variance. Higher percentages of the total variance explained is an indicator of strong relationship between group of variables in this study. From the table it is understood that the variables under the study are grouped as five factors with the Eigen value of more than 1.0.

\section{Scree Plot for Family Relations}

In multivariate statistics, a scree plot is a line plot of eigenvalues of factors or principal components in an analysis (Raymmond B. Cattell). It helps to find the number of factors to retain in an exploratory factor analysis or principal components to keep in a principal component analysis (PCA) (Wikipedia).

Figure 1 - Eigen Value and Number of Items

Scree Plot

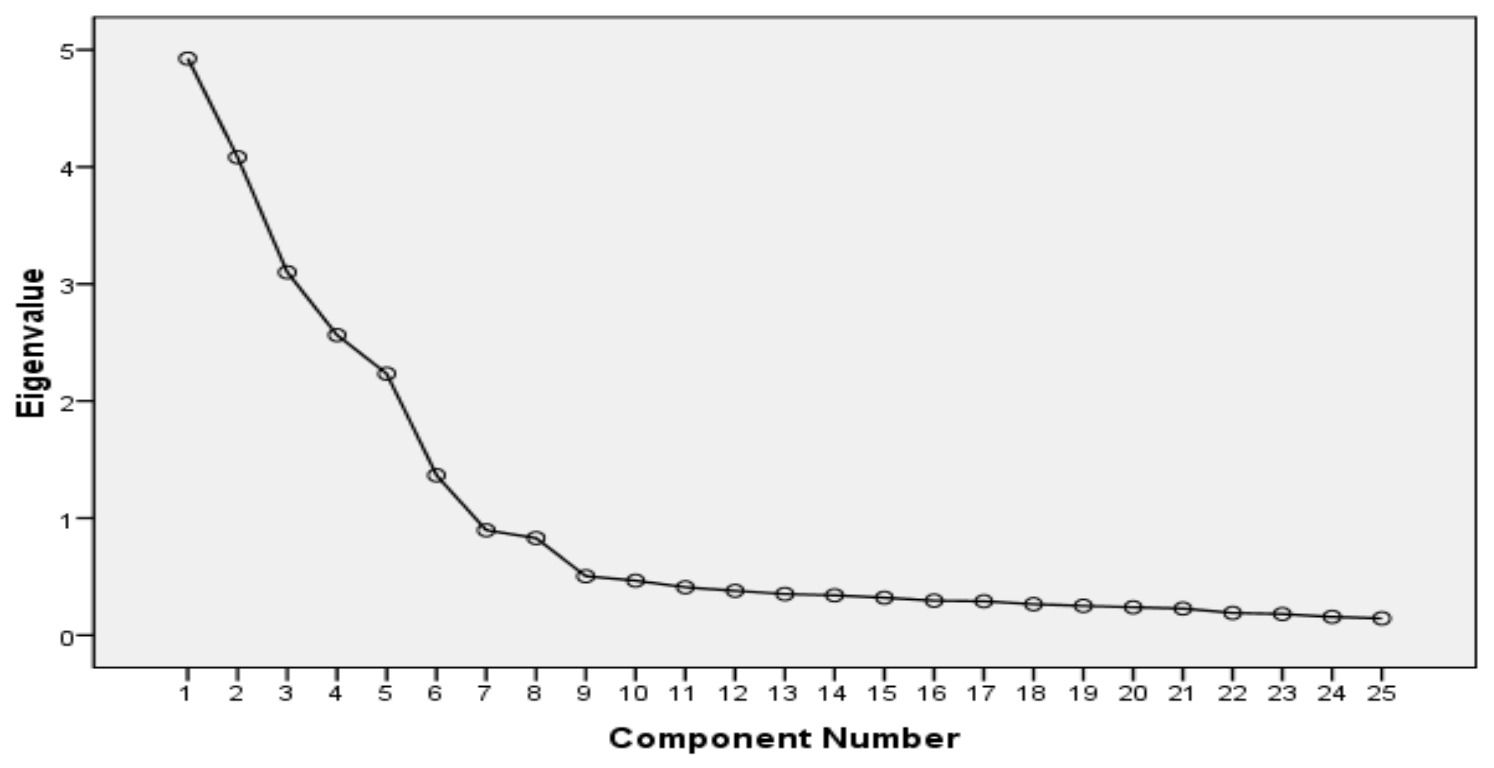

\begin{tabular}{|c|c|c|c|c|c|}
\hline \multicolumn{6}{|c|}{ Rotated Component Matrix } \\
\hline \multirow[b]{2}{*}{ Item } & \multicolumn{5}{|c|}{ Component } \\
\hline & \begin{tabular}{|l} 
Factor \\
Loading
\end{tabular} & \begin{tabular}{|ll} 
Factor & Label \\
constructs &
\end{tabular} & $/ \mid \begin{array}{l}\text { Convergent } \\
\text { Validity }\end{array}$ & AVE & $\begin{array}{l}\text { Discriminant } \\
\text { Validity }\end{array}$ \\
\hline FAUD1 & .886 & \multirow{6}{*}{$\begin{array}{l}\text { Family } \\
\text { Misunderstanding }\end{array}$} & \multirow{6}{*}{0.841167} & \multirow{6}{*}{0.7389263} & \multirow{6}{*}{0.813} \\
\hline FAUD2 & .882 & & & & \\
\hline FAUD3 & .836 & & & & \\
\hline FAUD4 & .833 & & & & \\
\hline FAUD5 & .823 & & & & \\
\hline FADU6 & .787 & & & & \\
\hline FSS1 & .890 & \multirow{4}{*}{ Family Support } & \multirow{4}{*}{0.869} & \multirow{4}{*}{0.755627} & \multirow[t]{4}{*}{0.844} \\
\hline FSS2 & .889 & & & & \\
\hline FSS3 & .858 & & & & \\
\hline FSS4 & .839 & & & & \\
\hline FDST1 & .871 & Family Distrust & 0.85225 & 0.740233 & 0.810 \\
\hline
\end{tabular}




\begin{tabular}{|c|c|c|c|c|c|}
\hline FDST2 & .857 & & & & \\
\hline FDST3 & .853 & & & & \\
\hline FDST4 & .828 & & & & \\
\hline FIS2 & .921 & \multirow{3}{*}{ Family Isolation } & \multirow{3}{*}{0.915667} & \multirow{3}{*}{0.838476} & \multirow{3}{*}{0.878} \\
\hline FIS1 & .918 & & & & \\
\hline FIS3 & .908 & & & & \\
\hline FINT2 & 799 & \multirow{3}{*}{ Family Interaction } & \multirow{3}{*}{0.780333} & \multirow{3}{*}{0.609335} & \multirow{3}{*}{0.757} \\
\hline FINT3 & .790 & & & & \\
\hline FINT1 & .752 & & & & \\
\hline \multicolumn{6}{|c|}{$\begin{array}{l}\text { Extraction Method: Principal Component Analysis. } \\
\text { Rotation Method: Varimax with Kaiser Normalization. }\end{array}$} \\
\hline \multicolumn{6}{|c|}{ a. Rotation converged in 5 iterations. } \\
\hline
\end{tabular}

FAUD - Family Misunderstanding; FIS - Family Isolation; FSS- Family Support; FDST- Family Distrust; FINT - Family Interaction

The five components with Eigen value greater than 1.0 were rotated using varimax rotation in order to execute orthogonal solution which is shown in the table. Varimax rotation is the most highly utilised method to produce an orthogonally rotated matrix. It is generally accepted that loadings should be 0.50 or greater to provide any interpretive value. A loading is simply the Pearson correlation between the variable and the extracted component. The greater the loading, the more and the more variable is a pure measure of the component.

Component 1 contains six variables or $21.61 \%$ of the total variables included in the study. Six variables load in the factor one shows an excellent range of variable representation in the factor. The six variable loaded in factor one represents understanding aspects in the family with positive and reverse coded items. Majority of the items in the factor one among the six variables represent understanding aspects of family with the reverse coded attributes is labeled as family misunderstanding. The convergent validity of six measured items on underlined factor of family misunderstanding (Alan Sillars, 2011) is 0.841 and which shows good convergence. The average variance is extracted is more than $0.5(0.73)$ explains the better variance. The obtained discriminant validity is 0.813 and which is more than the maximum shared value of total item correlation. There are four variables which are converged with the correlation value of more than 0.7 constitute a factor with $16.431 \%$ of variance explained. The four variables grouped under factor two represent positive aspects of family support to the students is labelled as family support. The required convergent validity, average variance extracted and discriminant validity are more than 0.5 shows that the four variables are effectively loaded under factor two.

Factor three is labelled as family distrust which comprises of four variables with the loading of more than 0.7. All the four variables are reversely coded. The four variables under family distrust explain $15.152 \%$ of variance about the construct. The convergent validity of four variables under distrust is more than $0.7(0.85)$. The average variance explained 
is 0.74 and which is more than 0.5 . The discriminant validity obtained is 0.81 .

Factor four comprised three variables with the loading of more than 0.7 represent a factor named as family isolation. All the three items are reverse coded and which describes student issues on the relationship of family. It represents $13.166 \%$ of variance of the factor with the convergent validity of 0.91 , average variance extraction of 0.83 and discriminant validity of 0.878 .

Factor five is labelled as family interaction comprises three variables with the factor loading of more than 0.7. All the three items are positive statements which explain $10.9 \%$ of variance about the factor family interaction. The required convergent validity, average variance and discriminant validity were obtained for the factor through the loaded variables $(0.7,0.6$ and 0.57 respectively).

By the application of factor analysis in order to extract the latent factors related to family relation are identified as five major factors namely family misunderstanding, family support, family distrust, family isolation and family interaction.

\section{Discussion}

Adolescence is a period of freedom and autonomy (Steingber, L, 1999) for an individual. It is a period of rapid growth and development. Psychologist feel it is a stage where new relationships are formed and old relationships are transformed based on the needs and interest of the individual. This transition period brings in unique challenges (Jodi Quas, 2014) in every adolescent child. Family being the basic social unit of the child has to offer more to the adolescent child. Though love governs the family bonding, responsibilities of adolescents increase and this has an impact on his or her relationship within the family to a greater extent. One important factor when it comes to family relations is trust. It is one aspect every adolescent wants to have from their parents. In the instrument, 4 statements reflect significantly on family distrust. (Item No. 16, 22, 24, \& 25). If mutual trust is higher relationships are stronger. When trust deficit happens it affects interaction. For all major crisis to grow big, psychologist admit lack of communication as the core factor. Family interaction strengthens family bonding (Saptawati et al., 2017) and better communicating attitude and cultural present in the family will do a world of good to adolescent child. Sharing and interacting relieves undue stress (Mark Stibich, 2020) and it was analysed that family interaction strengthens family relations (Barry, A, Garst et al., 2013). Three items depict family interaction (Item No. 18, 19, \& 20) in the instrument. If the interaction between the adolescent child and rest of the family members are constantly interrupted without proper remedy quickly will lead to the child feeling isolated (U.S. Department of Education, p.6) in the family. In the instrument (Item No. 11, 12, \& 13) three statements reflect on this particular variable. Isolation being a silent killer of family relations (Meagan C. Tucker and Christina M. Rodriguez, 2014) has to be negated for healthy family relations. At times adolescents feel isolated and positive support coupled with clear unbiased discussion and empathical attitude of the family members will help the child to overcome crisis. Hence at all times family support (Lemos et al. 2011) will be the backbone of individual's growth and development. Family support is not just limited to adverse situations but constantly shaping the development process throughout this stage. It helps to see the world positively and prepare the individual to meet the challenges and welcome opportunities with gladness. Family support construct is identified by four statements (Item No. 1, 2, 4, \& 5). When adolescent child lacks or feels he/she lacks in terms of family support (Berta Schnettler, et al., (2014), trust, feels isolated, and because of which starts to avoid by interacting less with the members of family, the individual ends up in misunderstanding with the members of family. Six statements combined to reflect this construct of family misunderstanding (Item No. 3,6,7,9, 21, \& 23). Misunderstanding creates a whole lot of damage to relationships and family misunderstanding could be avoided by proper support and better interaction (Angeliki Tzanne, 2015) within the members of the family. Though it is bound to happen it is the ability to bounce back, i.e., the time taken to be normal depends to a greater extent on family support. Hence during adolescence, parents role becomes crucial (Sells, S. 1998) in maintaining the overall functioning of the family and particularly their relationship with their adolescent child.

The extracted constructs are named based on research reviews and the combination in which the statements have been correlated statistically in EFA. The number of statements after EFA is 20 with 9 positive and 11 negative statements respectively.

\section{Conclusion}

As adolescence is a period of transition family relations during this period is a challenge. Though some go through is without much of difficulty, many feel challenged. Exploratory factor analysis has identified, family misunderstanding (Ruksana Saikia, 2017), family support (Schnettler et al., 2013b), family distrust, family isolation and family interaction (Ong et al. 2013) as the major attributes of family relations 
among higher secondary adolescents of Kanchipuram District, Tamil Nadu, India. Hence it is important that parents show proper support (Judith G. Smetana and Wendy M. Rote, 2019) during this stage so that adolescents move on this important period smoothly.

\section{References}

[1] Acock, A. C., \& Demo, D. H. (1999). Dimensions of family conflict and their influence on child and adolescent adjustment. Sociological Inquiry, 69, 641658.

[2] Angeliki Tzanne, (2015, June, 19). Miscommunication and misunderstanding. The Encyclopedia of Applied Linguistics. https://doi.org/10.1002/9781405198431.w beal1461

[3] Barry A Garst, Sarah Baughman, Nancy Franz \& Richard W. Seidel (2013). Strengthening Families: Exploring the impacts of Family camp experience of Family functioning and parenting, Journal of Experiential Education. 36(1), 65-77. DOI: $10.1177 / 1053825913481582$

[4] Berta Schnettler, Marianela Denegri Coria, Horacio Miranda, Jose Andres Sepulveda, Ligia Maria Orellana, Galo Paiva and Klaus G Grunert, (2014). Family support and subjective well-being: An exploratory study of University students in southern Chile, Social Indicators Research. 122(3), DOI: 10.1007/s11205-014-0718-3

[5] Gidden, A. (1997). Sociology. Cambridge: Polity Press.

[6] Hair, J., Black, W., Babin, B., \& Anderson, R. (2010). Multivariate Data Analysis (7th edn. ed.). Jew Jersey: Prentice-Hall Inc.

[7] Jodi A. Quas, (2014, December). "Adolescence: A unique period of challenge and opportunity for positive development" CYF News. https://www.apa.org/pi/families/resources/ newsletter/2014/12/adolescencedevelopment

[8] Judith G. Smetana and Wendy M. Rote, (2019). Adolescent-parent relationships: Progress, processes and prospects, Annual Review of Developmental Psychology,1,
41-68. https://doi.org/10.1146/annurevdevpsych-121318-084903

[9] Jude J. Obiunu. (2015). Relationship between parents and peer influences on qualities of adolescent friendship. Journal of Education and Practice,6(8), 128-133.

[10] Lemos V., Nunes, M., \& Munhoz, A. (2011). Supporte Familiar, Crencas Irracionals e Sintomatologia Depressiva em Estudantes Universita Rios. Psicologia Ciencia E Profissao, 31(1), 20-29.

[11] Mark Stibich, (2020, February 4) . "How to Manage Stressful People in Your Life". Stress Management, Management Techniques, Verywell mind.https://www.verywellmind.com/how -to-manage-stressful-people-2223890

[12] Mark, G. M. (2008). The relationship between workplace stress and job characteristics, individual differences, and mental health. ProQuest LLC 2013.

[13] Meagan C. Tucker and Christina M. Rodriguez, (2014). Family Dysfunction and social isolation as moderators between str3ess and child physical abuse risk. Journal of Family Violence, 29(2), 175-186. DOI 10.1007/s10896-013-9567-0

[14] N.M. Webb, R. S. (2006). Reliability Coefficients and Generalizibility Theory. Retrieved 2017, from https://www.researchgate.net.

[15] Ong, Q., Ho, K. W., \& Ho, K. C. (2013). Alturism within the family: A comparison of father and mother using life happiness and life satisfaction. Social Indicators Research, 111, 485-510.

[16] Popkin, M. (1993). Active Parenting Today: For Parents of 2 to 12 years olds. Parents Guide. Marietta, GA: Active Parenting Publishers.

[17] Ruksana Saikia, (2017). Broken family: Its causes and effects on the development of children, International Journal of Applied Research.3(2), 445448.

[18] Saptawati Bardosono, Rinin Sekartini, Dian Novita Chandra, Yulianti Wibowo (2017). Bonding Development between parents and children through playing together to improve family 
happiness, World Nutrition Journal, 1(1), 41. DOI: $10.25220 / W N J . V 01 i 1.0009$

[19] Schnettler, B., Peria, J.P., Mora,M., Miranda, H., Sepulveda, J., Denegri, M., et al. (2013b). Food-related lifestyles and eating habits inside and outside the home in the Metropolitan Region of Santiago, Chile. Nutricion Hospitalaria, 28(4), 12661273.

[20] Selekman, M., D. (1997). Solutionfocussed therapy with children: Harnessing family strengths for systemic change, Guilford Press, New York How do i parent my adolescent?

[21] Sells, S. (1998). Treating the tough adolescent: A family-based. Step-by-step guide, Guilford Press, New York.

[22] Sillars, A. L. (2009). Interpersonal conflict. In C. Berger, M. Roloff, and D. R. Roskos-Ewoldsen (Eds.). Handbook of communication science ( $2^{\text {nd }}$ ed.)(pp.273289). Thousand Oaks, CA: Sage.

[23] Sillars, Alan. (2011). Motivated misunderstanding in family conflict discussions. Managing Interpersonal Sensitivity: Knowing When - and When Not - To understand Others. 193-213.

[24] Steinberg, L. (1999). Adolescence ( $5^{\text {th }}$ Ed.). Boston: McGraw-Hill, p. 276.

[25] Tabachnick, B. G., \& . Fidell, L. S. (2013). Using Multivariate Statistics (6th Edition ed.). California: Pearson.

[26] U.S. Department of Education. (2002, January, 8). Helping your child through early adolescence. ED Pubs, Education Publications Center, Jessup, MD 20794-1398.

[27] Walter W. Hudson. (1977). Index of Family Relations, The Mind Test. In Rita Aero and Elliot Weiner, pp. 103 William Marow and Company, Inc, NY, 1981.

\section{Web Sources \\ [1] http://en.m.wikipedia.org/wiki/Scree_pl ot}

[2] http://statwiki.kolobkreations.com/index.p hp?title=Exploratory_Factor_Analysis\#M aximum_Likelihood_.28ML.29. Retrieved March 15, 2017, from Statwiki: http://statwiki.kolobkreations.com 